Energy Research Journal 2 (2): 51-56, 2011

ISSN 1949-0151

(C) 2011 Science Publications

\title{
An Automatic Incubator
}

\author{
Siriluk Sansomboonsuk, Chagorn Phonhan and Girati Phonhan \\ Faculty of Engineering, Mahasarakham University, Mahasarakham, 44150, Thailand
}

\begin{abstract}
The designing of an automatic incubator consists of three main parts. The first part is a mathematical model of an incubator. Thermo-physical properties of selected materials were substituted to investigate its heat transfer characteristics. The second part is the consideration of equipment used to measure and control temperature and humidity. The last part is to select the controller for an inclined egg tray. In this study the incubator was designed to incubate $30 \mathrm{eggs}$ each time. The dimension of incubator cabinet was $0.47 \times 0.48 \times 0.41 \mathrm{~m}$. Within the incubator cabinet, the temperature of $37^{\circ} \mathrm{C}$ and humidity of $60 \%$ RH was set. Inside wall made from Zinc sheet and outside wall made from Acrylic plastic sheet. Insulation was plywood. Four lamps of 60 Watt halogen were selected as a heat source. Inside cabinet, two little fans were installed for air ventilation. An AP 104 board received input signals from thermocouple type $\mathrm{K}$ and connected to a relay. This board utilized for measuring and control temperature and humidity. To control the angle of the inclined egg tray, a limit switch was used. From testing the measuring and control system without egg, the results shown that measuring and control system gave high accuracy. From incubation experiments of the hatching eggs, the average of the chick biddy hatched $81.665 \%$.
\end{abstract}

Key words: Incubator, hatching, hatching egg, temperature control

\section{INTRODUCTION}

The commercial poultry industry in Thailand has been a leader among all agricultural commodities. In 2008, International Animal Quarantine Station, bureau of disease control and veterinary service and Office of Livestock Standard and Certification (2008) reported that the income from exporting for chicken meat and product were about 41 billion Baht. The reasons for this ascension to the top of popular food products (meat and eggs) list were many. They were nutritional, economical, versatile in preparation and available in many different food products. It was remarkable that the egg industry provided a substantial contribution to the agricultural economy of Thailand. Therefore, it was necessary to improve efficiency and productivity of the poultry industry. According to customer demand, the increasing of higher food quality and safety were needed.

Reproduction in chicken was a process that functioned very efficiently for the success of the poultry industry. Novice poultry producers usually became interested in artificial incubation of their own chicks. In Thailand, the poultry producers usually used mercury thermometers to measure temperature and humidity in the incubator cabinet. The thermostat was used for adjusting temperature. The results of incubation were commonly poor with improper control temperature and humidity control. Eggs were turning done by hand or used the manually sway. This required time consuming because eggs must be turned at least 4-6 times daily during the incubation period. Hence, a well designed incubator was essential expectation.

The aim of this study was to apply new technology to enhance the efficiency of the incubator. The qualification of the incubator was reasonable structure, compact appearance, high efficiency, easy to operate and maintain, lowest possible cost.

This study contains the information of a simple modeling incubation temperature, design and construction of a small incubator, the experiments and results. The last information is conclusions and recommendations.

\section{MATERIALS AND METHODS}

A mathematical model of an incubator: A simple model was derived to describe heat transfer characteristics of the incubator by presenting the relationship between temperature and the incubation time. In this study the incubator was specifically designed for single state incubation, which will hold

Corresponding Author: Siriluk Sansomboonsuk, Faculty of Engineering, Mahasarakham University, Mahasarakham, 44150, Thailand 
about 30 eggs. For the convenient derivation, type of incubator was still-air. Incubator located in a fit temperature room. From Energy conservation for the stationary closed system, the kinetic and potential energy did not change (Ozisik, 1985).

Therefore, the relationship between heat transfer and temperature change was Eq. 1:

$\mathrm{Q}_{\mathrm{IN}}-\mathrm{Q}_{\mathrm{LOSS}}=\mathrm{mc}_{\mathrm{v}} \mathrm{dT} / \mathrm{dt}$

Equation 1 can write in the form of finite difference as Eq. 2 and 3:

$$
\begin{aligned}
& \frac{T(t+\Delta t)}{\Delta t}=\left(\frac{Q_{\text {in }}-Q_{\text {loss }}}{\mathrm{mC}_{\mathrm{v}}}\right) \\
& \mathrm{T}(\mathrm{t}+\Delta \mathrm{t})=\Delta \mathrm{t}\left(\frac{\mathrm{Q}_{\text {in }}-\mathrm{Q}_{\text {loss }}}{\mathrm{mC}_{\mathrm{v}}}\right)+\mathrm{T}(\mathrm{t})
\end{aligned}
$$

$\mathrm{Q}_{\text {loss }}$ was considered from heat lost by conduction and convection of incubator walls. Equation of $\mathrm{Q}_{\text {loss }}$ was shown in Eq. 4:

$$
\mathrm{Q}_{\text {loss }}=\left(\left[\left(\mathrm{U}_{1} \mathrm{~A}_{1}+\mathrm{U}_{2} \mathrm{~A}_{2}+\mathrm{U}_{3} \mathrm{~A}_{3}\right)\left(\mathrm{T}(\mathrm{t})-\mathrm{T}_{\mathrm{atm}}\right)\right]\right)
$$

Hence, from Eq. 3 and 4 the relationship between temperature and time were Eq. 5:

$$
\begin{aligned}
\mathrm{T}(\mathrm{t}+\Delta \mathrm{t})= & \frac{\Delta \mathrm{t}}{\mathrm{mC}_{\mathrm{v}}}\left(\mathrm{Q}_{\text {in }}-\left[\left(\mathrm{U}_{1} \mathrm{~A}_{1}+\mathrm{U}_{2} \mathrm{~A}_{2}+\mathrm{U}_{3} \mathrm{~A}_{3}\right)\right.\right. \\
& \left.\left.\left(\mathrm{T}(\mathrm{t})-\mathrm{T}_{\mathrm{atm}}\right)\right]\right)+\mathrm{T}(\mathrm{t})
\end{aligned}
$$

Where:

$\mathrm{Q}_{\text {in }}=$ Heat input to incubator (Watts)

$\mathrm{Q}_{\text {loss }}=$ Heat lost by conduction and convection (Watts)

$\mathrm{T}=$ Temperature of incubator $(\mathrm{K})$

$\mathrm{T}=$ Time $(\mathrm{sec})$

$\mathrm{m}=$ Mass of air inside incubator $(\mathrm{kg})$

$\mathrm{C}_{\mathrm{v}}=$ Heat capacity of air $\left(\mathrm{kJ}(\mathrm{kg} \cdot \mathrm{K})^{-1}\right)$

$\mathrm{U}_{1}=$ Overall heat transfer of vertical plate

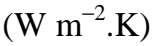

$\mathrm{U}_{2}=$ Overall heat transfer of horizontal plate; hot surface facing down $\left(\mathrm{W} \mathrm{m}^{-2}\right.$. $\left.\mathrm{K}\right)$

$\mathrm{U}_{3}=$ Overall heat transfer of horizontal plate; hot surface facing up $\left(\mathrm{W} \mathrm{m}^{-2}\right.$. $\left.\mathrm{K}\right)$

$\mathrm{A}_{1}=$ Area of vertical wall $\left(\mathrm{m}^{2}\right)$

$\mathrm{A}_{2}=$ Area of top horizontal wall $\left(\mathrm{m}^{2}\right)$

$\mathrm{A}_{3}=$ Area of bottom horizontal wall $\left(\mathrm{m}^{2}\right)$

$\mathrm{T}_{\mathrm{atm}}=$ Atmosphere temperature $(\mathrm{K})$
Equation 5 was a simple form of mathematical model of a small incubator. This model was used to examine the behavior of the designate incubator by substitution the thermo-physical properties of selected materials in the equation. The calculation and experimental results were compared and presented in the experiments and results.

Design and construction: Size and type of incubator depended on the needs and future plans of each producer. Many different models were available. In this study, a single stage incubator was designed, because all eggs in the unit were set on the same stage of incubation. To insure the best possible incubation, the key environmental factors needed for artificial incubation; temperature, humidity, airflow; were considered. Note that the incubator in this study scope only on chick egg incubation.

Temperature: Temperature was the most important factor in the incubation. The best hatch obtained by keeping the temperature at $37.5^{\circ} \mathrm{C}$ throughout the incubation period when using a forced-air incubator. Minor fluctuations (less than $0.5^{\circ} \mathrm{C}$ ) above or below were $37.5^{\circ} \mathrm{C}$ tolerated, but did not let the temperatures vary more than a total of $1^{\circ} \mathrm{C}$ (Jeffrey et al., 2008).

Humidity: Humidity was carefully controlled to prevent unnecessary loss of egg moisture. The relative humidity in the incubator between setting and three days prior to hatching should remain at 58-60\%, wetbulb. If the relative humidity inside the incubator was too low or too high, there was a hatching problem called red hocks. These chicks could possibly suffer from weak legs (Jeffrey et al., 2008).

Air ventilation: Ventilation played a role in cooling an overheated machine as well as making sure the oxygen: Carbon dioxide exchange was maximized. The internal fan speeds were very important and should be roughly $7200 \mathrm{rpm}$ (Jeffrey et al., 2008).

Positioning and turning: Egg is positioning in the incubator and turning ensured that the embryo was fully developed and in position to hatch. Common practice in the chicken was to set the eggs vertically with the air cell at the top of the egg. Any eggs that were positioned on their sides should be turned on their long axis. This means the eggs were set at a $45^{\circ}$ angle, after a $90^{\circ}$ turn; they face $45^{\circ}$ in the other direction (Jeffrey et al., 2008). 


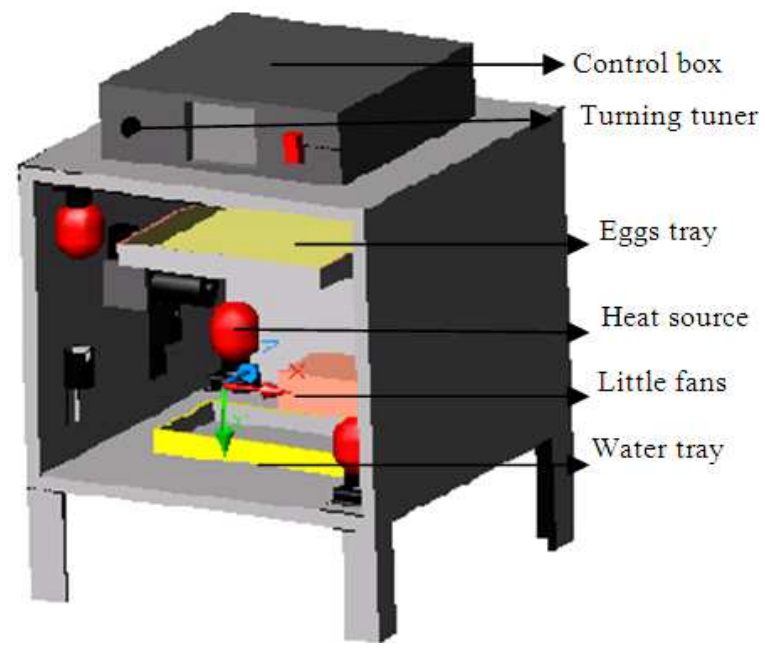

Fig. 1: The design structure of an incubator

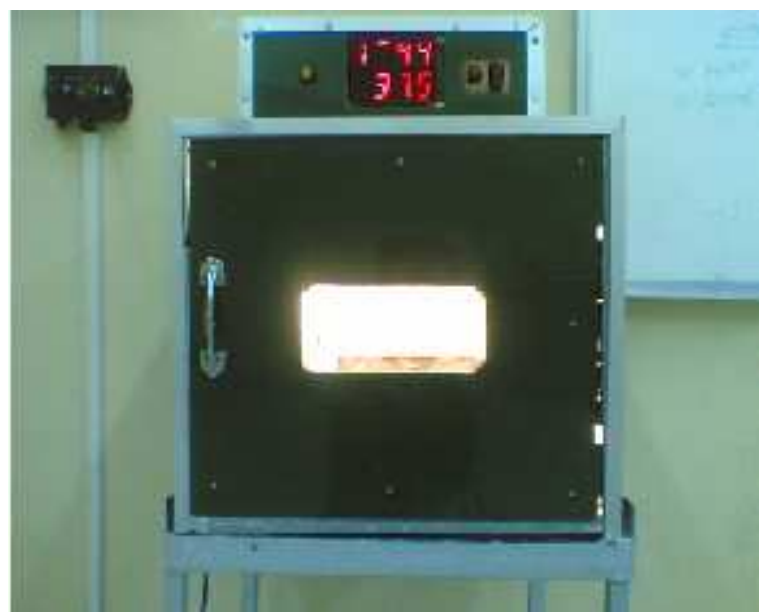

Fig. 2: Incubator outside aspect

Regarding the information listed above, which was the important factors for artificial incubation, an automatic incubator was then designed. This machine contained one tray of 30 eggs. The dimension of incubator cabinet was $0.47 \times 0.48 \times 0.41 \mathrm{~m}$. For the permanent and inexpensive to operate, inside wall was constructed of zinc sheet, whereas outside wall was an acrylic plastic sheet. The insulation was constructed from plywood. The heat source was four lamps of 60 Watts halogen. Water tray was placed on the bottom floor of cabinet to increase and recover humidity in cabinets. Thermocouple type $\mathrm{K}$, was selected to measure temperature and humidity in cabinets. An AP104 board worked for control temperature and humidity. Two little fans were also installed to ventilate air inside cabinet. Limit switch was installed outside the cabinet to manually turned eggs tray.

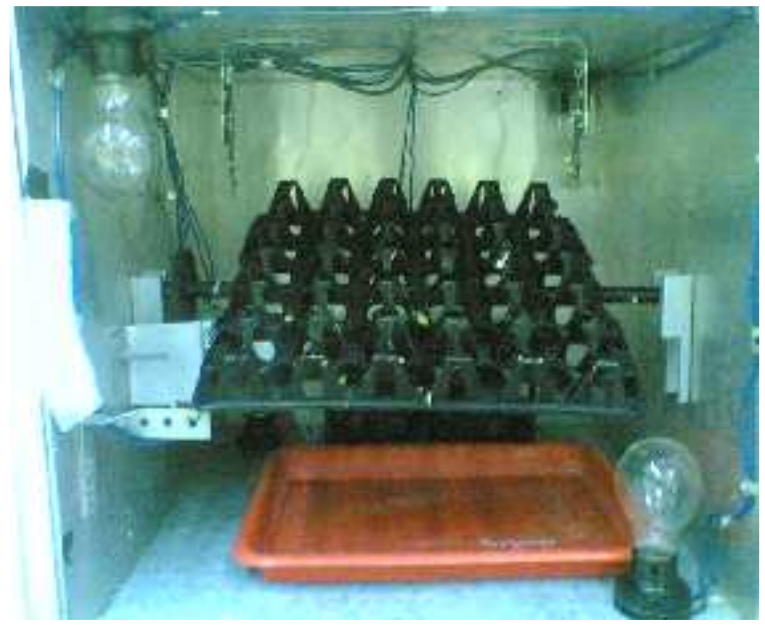

Fig. 3: Incubator inside aspect

From the detail of designing incubator, Eq. 5 became to Eq. 6 by substitution the thermo-physical properties of selected materials:

$$
\begin{aligned}
\mathrm{T}(\mathrm{t}+\Delta \mathrm{t})= & \frac{\Delta \mathrm{t}}{(\rho * 0.092)(1.005)}(0.24-0.01644) \\
& \left.\left.\left(\mathrm{T}(\mathrm{t})-\mathrm{T}_{\text {atm }}\right)\right]\right)+\mathrm{T}(\mathrm{t})
\end{aligned}
$$

where, $\rho$ is air density $\left(\mathrm{kg} \mathrm{m}^{-3}\right)$.

Figure 1 shows the assembly designed structure of the automatic incubator. Figure 2 and 3 show outside and inside of the incubator after completely constructed.

\section{RESULTS AND DISCUSSION}

Experiments and results: This study performs three main experiments. The first experiment was to determine the accuracy of the measuring instrument. The second experiment was done for testing overall of the machine system. The third experiment was the incubation hatching eggs.

The accuracy of measure instrument: A mercury thermometer was placed in the incubator to serve as a standard to check the incubator sensor. Moreover, to recheck the accuracy sensor of incubator, Testo 625 was used to measure temperature and humidity. The results of this experiment were presented in Table 1 and 2. Error 1 and 3 were calculated by using the results from mercury thermometer as standardization. On the other hand, Error 2 and 4 used results from Testo 625 as standardization. 
Table 1: Temperature results

\begin{tabular}{|c|c|c|c|c|}
\hline \multicolumn{3}{|l|}{ Temperature $\left({ }^{\circ} \mathrm{C}\right)$} & \multirow{2}{*}{\multicolumn{2}{|c|}{ Error (\%) }} \\
\hline \multirow[b]{2}{*}{ AP 104 board } & \multirow{2}{*}{$\begin{array}{l}\text { Testo } \\
625\end{array}$} & \multirow{2}{*}{$\begin{array}{l}\text { Mercury } \\
\text { thermometer }\end{array}$} & & \\
\hline & & & 1 & 2 \\
\hline 39.7 & 37.80 & 40.000 & 0.75 & 0.500 \\
\hline 38.2 & 37.40 & 38.000 & 0.52 & 2.130 \\
\hline 37.8 & 37.30 & 37.500 & 0.80 & 1.340 \\
\hline 37.3 & 37.40 & 37.000 & 0.80 & 0.260 \\
\hline 36.9 & 36.20 & 37.500 & 1.60 & 0.800 \\
\hline \multicolumn{3}{|c|}{ Average error (\%) } & 0.89 & 1.006 \\
\hline
\end{tabular}

Table 2: Humidity results

\begin{tabular}{|c|c|c|c|c|}
\hline \multicolumn{3}{|c|}{ Humidity (percentage of RH) } & \multirow{2}{*}{\multicolumn{2}{|c|}{ Error (\%) }} \\
\hline \multirow[b]{2}{*}{ AP 104 board } & \multirow{2}{*}{$\begin{array}{l}\text { Testo } \\
625\end{array}$} & \multirow{2}{*}{$\begin{array}{l}\text { Mercury } \\
\text { thermometer }\end{array}$} & & \\
\hline & & & 3 & 4 \\
\hline 23 & 21.80 & 22.500 & 2.22 & 5.500 \\
\hline 24 & 22.10 & 23.200 & 3.44 & 8.590 \\
\hline 24 & 23.00 & 23.500 & 2.12 & 4.340 \\
\hline 24 & 23.40 & 23.800 & 0.84 & 2.560 \\
\hline 25 & 26.40 & 24.600 & 1.62 & 5.300 \\
\hline \multicolumn{3}{|c|}{ Average error $(\%)$} & 2.05 & 5.258 \\
\hline
\end{tabular}

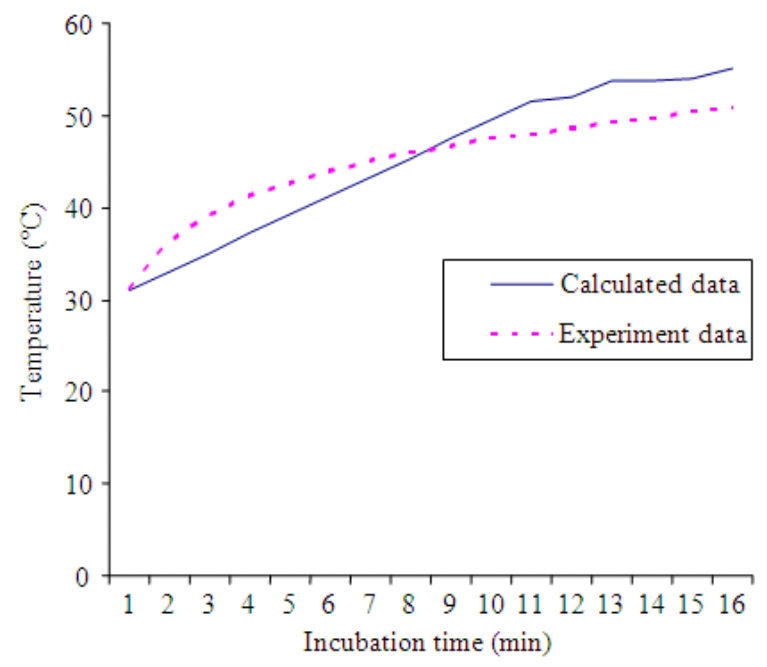

Fig. 4: Temperature from model and experiment

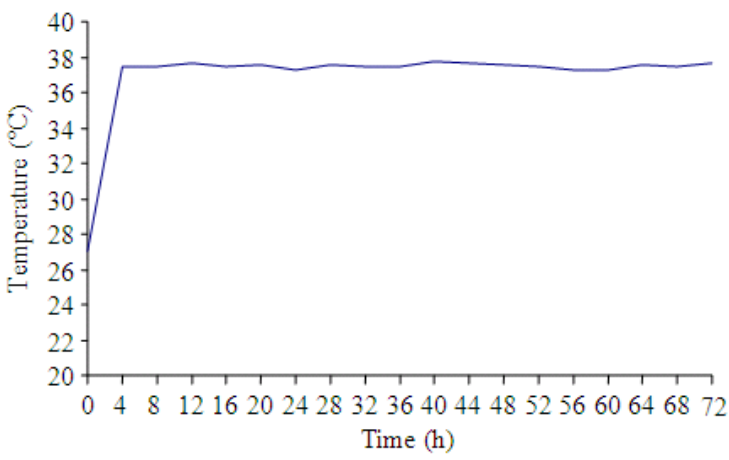

Fig. 5: Temperature from machine testing

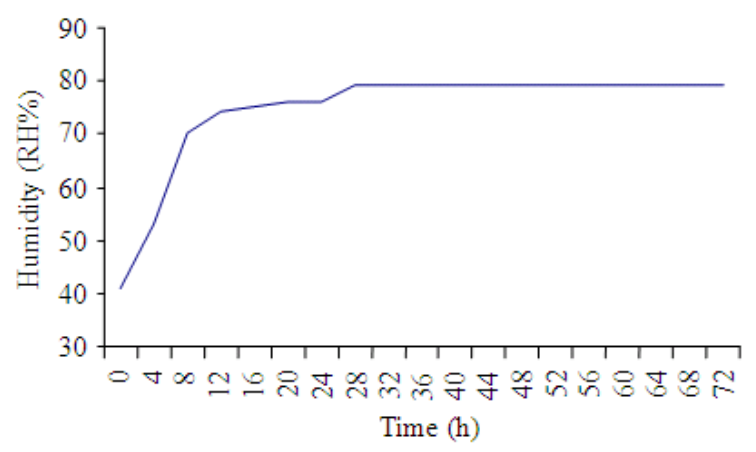

Fig. 6: Humidity from machine testing

Machine system testing: Overall systems such as measurement and control of temperature and humidity, turning system and air ventilation system were tested. The incubator was run without hatching egg about 3 days. The temperature was set to $37^{\circ} \mathrm{C}$ with humidity $79 \%$ RH. At the first $15 \mathrm{~min}$, temperature and humidity data were recorded 1 min each. The data was kept afterward every $4 \mathrm{~h}$ till 3 days. Figure 4 plots the relationship between temperature and incubator time calculated from mathematical model; Eq. 6 and measured from experiment to compare the result. The result of the machine running of $72 \mathrm{~h}$ also displayed in Fig. 5 and 6.

Hatching eggs Incubation: To incubate hatching eggs, there were six steps of the experiment. The first step was to keep the units indoor to protect incubator from major weather changes or maintain the uniform temperature and humidity. The ambient temperature and humidity were $27^{\circ} \mathrm{C}$ and $40 \% \mathrm{RH}$. The second step, selected 30 clean eggs from breeders, which were well developed, mature and healthy. The third step was recorded temperature and humidity every $4 \mathrm{~h}$. Generally, the incubation period of commercial chicks was 21 days (Smith, 2008). The temperature and humidity required for chicken incubation was set as Table 3 . The fourth step was turned eggs every $4 \mathrm{~h}$ during the incubation periods except the last three days before hatching. The fifth step, the eggs were candle at various stages of incubation to explore the size of the air cell. Compared the observing egg with Fig. 7 and 8 to see how successful was progressing The normal size of the air cell after 7,14 and 18 days of incubation for a chicken egg is shown in Fig. 7. Embryo chick after 10 days is presented in Fig. 8 The last step, assisted chicks during the hatch, if the chicks failed to break the shell after the $12 \mathrm{~h}$ duration. Slowly broke larger holes of egg starting with the two holes from the air cell end of the egg (Baby, 2007). 

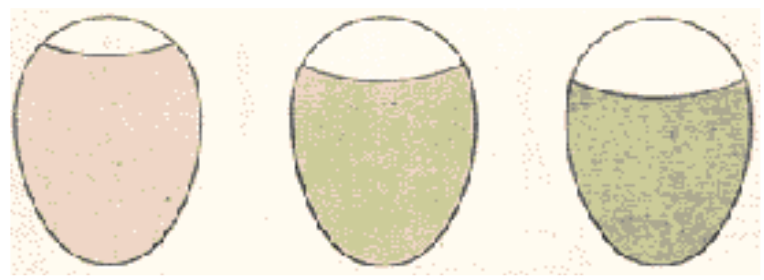

Fig. 7: Air cell size on 7th, 14th and 18th day (Baby, 2007)

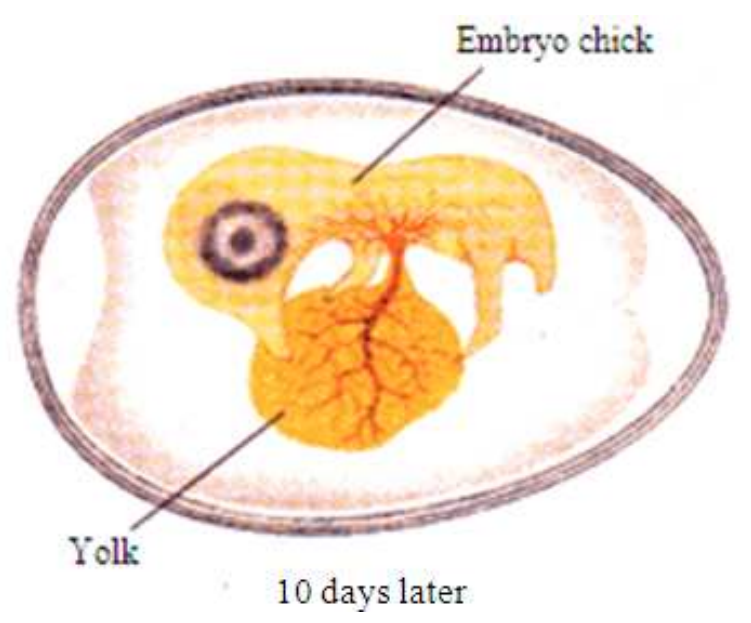

Fig. 8: Embryo chick after 10 days (Baby, 2007)

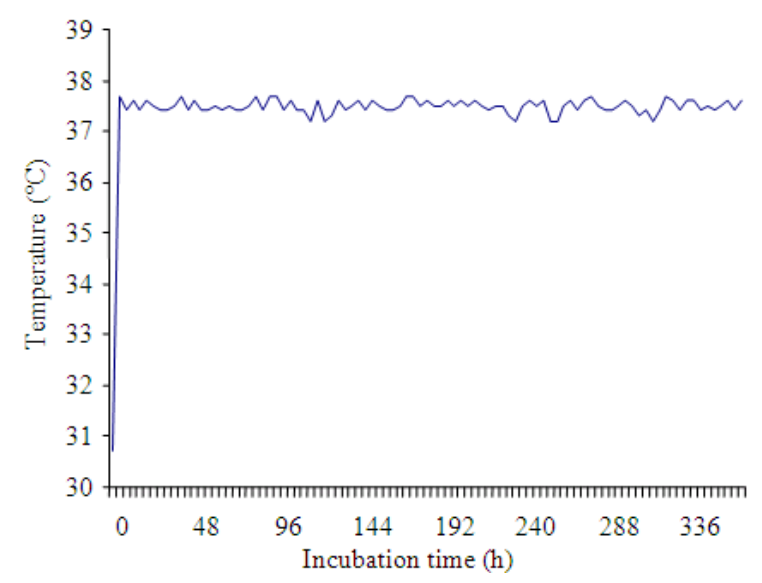

Fig. 9: Temperature during the incubation time

Table 3: Conditions for eggs hatching (tom)

\begin{tabular}{lll}
\hline Incubation period (days) & Temperature $\left({ }^{\circ} \mathrm{C}\right)$ & Humidity $(\mathrm{RH} \%)$ \\
\hline $1-18$ & 37.5 & 60 \\
$18-21$ & 37.0 & $61-65$ \\
\hline
\end{tabular}

Table 4: Number of success hatching

\begin{tabular}{lll}
\hline Series & Successful hatch (No. of chick) & Average hatch (days) \\
\hline 1st & 21 & 20 \\
2nd & 28 & 18 \\
\hline
\end{tabular}

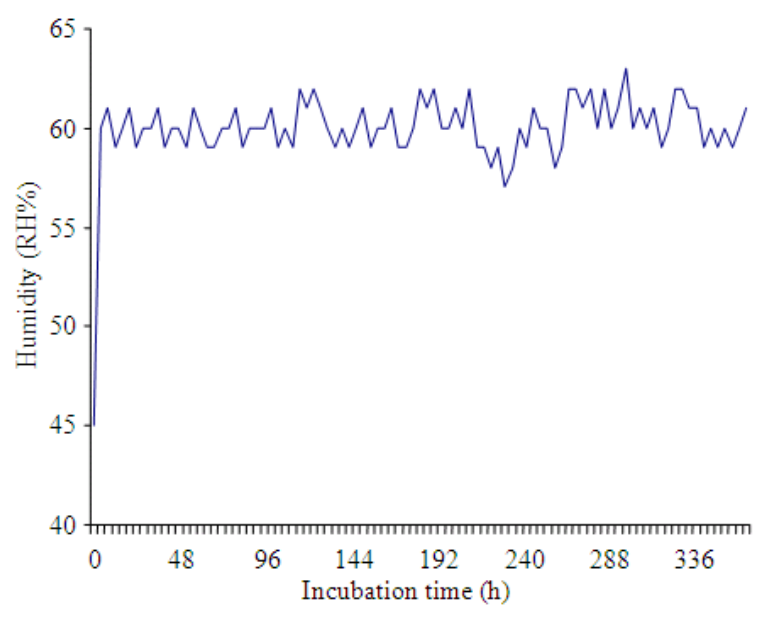

Fig. 10: Humidity during the incubation time

The third experiment was done for two series. Almost condition remained same just the interval time of egg candling was changed. The candling of the egg was done every day in the first series whereas in the second series, eggs were candled only the day 7th, 14th and 18th. Additional deviations were the humidity of the surrounding where uncertainty in the second series; the humidity fluctuates between $35-40 \% \mathrm{RH}$. The hatching result reported in the Table 4. The results of temperature and humidity in the incubator cabinet during incubation time presents subsequently in Fig. 9 and 10 .

\section{CONCLUSION}

- The design of automatic incubator was started from investigating heat transfer characteristics of incubator cabinet. Mathematical model of cabinet was created and referred. After studying the affecting factor for incubator, materials, size and other instrument were selected. The thermophysical properties of selected materials were replaced to the equation of the incubator model to predict the possible of construction. From the calculating, the result showed that selected materials; such as zinc sheet, plywood and acrylic plastic sheet, were suitability to construct the incubator cabinet. As shown in Fig. 4, the result from the model was good agreement with the result of the experiment

- The accuracy of measuring instruments were determined by using mercury thermometer and Testo 625 as standard. The error of temperature sensor was less than $1.1 \%$, whereat error of humidity sensor was under 5.3\%. It meant that measure sensor used in the incubator was acceptable instrument 
- The control system was tested about $72 \mathrm{~h}$ by an incubator running without hatching egg. As presented in Fig. 5 and 6, the experiments provided the best result of temperature and humidity control system. The level of temperature and humidity fluctuated between \pm 0.2

- From the experiments of chicks egg incubation, it could be found that the automatic incubator designed in this study contributed the advanced of incubation. The average of the hatch was $81.655 \%$

\section{Recommendations:}

- For more beneficial to developing incubator, the temperature and humidity control must be produced by the proper control. The temperature varies less than a total of $1^{\circ} \mathrm{C}$. The tuning system can be improved to be an automatic tuning system instead to by the installation of timing relay

- To develop a mathematical model for predicting the temperature in a cabinet, the condition of air inside cabinet considered to forced air. Moreover, effect of egg size and metabolic heat production of embryo of egg is needed to consider

- The incubator must be located in the area, which is kept at $25-27^{\circ} \mathrm{C}$ and is well ventilated

\section{REFERENCES}

Baby, C., 2007. New Life.

Jeffrey, J.S., G.P. Martin and R.C. Fanguy, 2008. The incubation of ratite eggs. Texas A\&M University System.

Ozisik, M.N., 1985. Heat Transfer: A Basic Approach. 1st Edn., McGraw-Hill, New York, ISBN-10: 0070479828, pp: 780.

Smith, T.W., 2008. Care and incubation of hatching eggs. Mississippi State University. 